\title{
Creating technology mentor teachers through a digital sabbatical opportunity on-line
}

\author{
Catherine P. Fulford, Rachel A. Rivers, Gary Theal and Celia Main-Anakalea \\ Educational Technology Department, University of Hawaii at Manoa
}

\begin{abstract}
Infusing modern learning technologies throughout the educational experience of pre-service teachers is a prime requisite of the PT3, LEI Aloha Project in the Department of Educational Technology at the University of Hawaii. Preproject surveys indicated that teachers need courses, time, convenient access, mentors, and support if they are to become proficient in the application of technology to meet curriculum standards. The Technology Intensive Enhancement Series coupled with Department of Education teacher sabbaticals, one-on-one hands-on Community College support, and extensive digital resources provide a continuum that responds to the expressed needs and the projected demand for technology-proficient teachers.
\end{abstract}

Key words: technology, digital resources, teacher, mentor, sabbatical, stakeholder

\section{NEED FOR TECHNOLOGY MENTOR TEACHERS}

The United States (US) will have to hire two million teachers in the next decade due to increased enrolment and the retirement of ageing teachers (US Department of Education, 1998). This problem affects not only the mainland US but also Hawai'i. According to projections, Hawai'i will require more than 5,000 teachers over the next seven years. This need presents both a challenge and an opportunity to create systemic programme improvements to infuse modern learning technologies throughout the educational experience of pre-service teachers. In response to Hawai'i's growing need for technology-proficient teachers, the College of Education (COE) at the University of Hawai'i's (UH) Learning Enhancement through Innovations (LEI) Aloha project in the Department of Educational 
Technology (ETEC) has been successfully creating an educational continuum of technology-intensive experiences for pre-service teachers. This continuum begins with pre-education courses taught in community colleges and concludes with field-based practice supervised by technology mentor teachers. One of the initial challenges facing the project was the struggle to find qualified technology mentor teachers. The solution has been the development of a sabbatical opportunity named the Technology Intensive Enhancement Series (TIES) designed to train them.

\subsection{Importance of the use of technology by mentors}

A major factor in teachers' technology use is the behaviour of those in supervisory roles during a teacher's pre-service field experiences. It is not enough for students to see technology modelled in their educational experience; they also need to see those technologies applied by their supervising or mentor teachers in the classroom. Carlson and Gooden (1998) found that technologies modelled at least once per week by $50 \%$ of supervising teachers became technologies with which pre-service teachers were comfortable. Authentic examples of how technology can be used as a tool to improve student learning are critical. Hinnant (1997) states that "the elements most crucial to the successful integration of technologies into teaching are teachers and their ability to use all their skills to inspire, motivate, challenge, and enrich their students". Positive role models are essential at this juncture and play a vital role in students' careers.

\subsection{Common challenges in teacher training}

Mentoring is an integral part of the teacher preparation system in the $\mathrm{COE}$ at UH. All teacher education students are paired with mentor teachers during their field experience. The problem has been finding enough mentors. Since the establishment of field-based cohorts, faculty cohort leaders have the additional pressure of locating their own mentor teachers to work with their students. These faculty members report that recruiting mentor teachers is not only extremely time consuming, but difficult due to a lack of motivated and willing teachers. Mentors who are qualified to support and model technology are even harder to find. Many teachers are not yet skilled in the various technologies and feel uncomfortable using technology in their classroom. Although training is needed, many teachers insist they lack the time to develop new skills. Attending evening or summer programmes increases an already burdensome teacher workload and requires a great deal of personal motivation and sacrifice. In a study involving full-time teachers in a parttime programme, students reported being very 'stressed' and cited time as 
their biggest problem, struggling to balance their course work, teaching, and the needs of their pupils.

The largest block of time teachers have specifically for professional development is a sabbatical. The Hawai'i Department of Education (DOE) receives 85 to 100 sabbatical proposals per year and is mandated to grant 50 at a cost of 1.5 million dollars. Even though $75 \%$ of the proposals request college courses, sabbatical administrators are concerned that many proposals cannot demonstrate their impact on teaching and learning. In addition, teachers wanting to attend a technology programme during their sabbatical, find many departments can only offer a chance to compete for the limited spaces in courses where priority is given to regular students. A sabbatical opportunity specifically designed to alleviate these problems was the best solution.

To be effective, a sabbatical programme would have to address issues of the state's geography, which is isolated from the mainland US by 3,000 miles of ocean. Its people live on seven islands and can only conveniently travel to other islands by air. The challenges of training technology mentors, such as vast distances, and teachers' time shortages and mentoring qualifications, are not unique to Hawai' $i$. To address these common concerns, the Technology Intensive Enhancement Series (TIES) on-line sabbatical opportunity was developed and provides useful examples of how technology can help solve some of the problems facing education.

\section{TECHNOLOGY MENTOR TRAINING AND SUPPORT}

\subsection{Technology Intensive Enhancement Series (TIES)}

TIES is a series of four professionally designed technology intensive, teacher education, on-line courses combined with a hands-on technology project course facilitated by a technology mentor. To help guide the preparation of teachers, the National Council for Accreditation of Teacher Education (NCATE) worked with the International Society for Technology in Education (ISTE) to develop educational technology standards for initial teacher certification (National Council for Accreditation of Teacher Education, 1996). TIES meets these National Educational Technology Standards (NETS) for teachers and requires students to use the NETS for students and their state content standards in developing their technology intensive lessons (ISTE, 1998 and ISTE, 2000). The goal of the courses is to produce technology-proficient teachers who can model and mentor others in 
infusing technology into the curriculum. TIES was developed as an educational opportunity for several target populations. In addition to inservice teachers, TIES can be taken by pre-service or uncertified teachers in outreach programmes throughout Hawai'i and American Samoa. The series is flexible and well suited for future teachers, as well as for in-service teachers interested in becoming technology mentors and leaders.

The CD-ROM and web-based resources for TIES supply a rich set of multi-media lessons and video-streamed models of how NETS are applied in real classrooms. Activities require hands-on use of technology and exploration of local, national, and international resources. Students are required to observe local teachers and engage in conversations with teachers globally. Students develop an electronic portfolio throughout the series. At the culmination of TIES, participants are able to apply the principles, theories, and methods of educational technology, recognise how technology supports standards-based learning, and mentor others in integrating technology into the curriculum.

\section{$2.2 \quad$ TIES courses}

The Educational Media and Technology course provides an introduction to theories, the application of principles, and acquisition of practical skills of educational technology to improve teaching and learning. Students learn to construct a variety of media and advocate uses for technology. Instructional design and visual literacy theories are used as a basis for developing lessons. Students work with a variety of technologies including digital video, graphics, projected visuals, e-mail, the world wide web, distance education, and multi-media.

The Computers in Education course provides an overview of basic components of computer systems and their application to instruction and administration. Students explore and evaluate various operating systems and software commonly used in schools. They use a variety of productivity tools to create technology-based assessment tools, and analyse data.

The Links to Life-Long Learning course provides students with an understanding and exploration of telecommunications as applied to life-long learning. Students have a focused exploration of the internet and its application to effective teaching and learning that includes finding, evaluating, using, and creating web pages. The course covers copyright law, ergonomics, privacy, security, ethics, and humanistic education.

The Technology Mentoring course is an 'action-research' course that allows students to apply the knowledge of technology operations, concepts, and integration learned in other courses. It provides the basis for developing positive mentoring relationships. Students learn to evaluate needs and set 
goals for mentoring. They learn to help others match content and technology standards, and develop effective technology-intensive learning environments. Students practice their mentoring skills by conducting technology-tutoring sessions. They conduct field-based analysis of technology resources in their schools, as well as locate virtual resources on the web.

The Special Technology Projects course provides a professional mentor and hands-on access to technology resources in statewide community colleges. Students develop an independent study plan in which they designate the technology projects they will complete, list technologies they will explore, self-assess their technology skills and identify the skills they will have gained by the time of course completion. Students document their progress by updating an electronic portfolio. The professional mentor directs students to tutorials and examples, as well as providing personal assistance and expertise. Technology resources allow participants to gain experience using computers, digital projectors, digital cameras, scanners, and a variety of software.

\subsection{Technology mentoring practicum}

An optional Technology Mentoring Practicum course provides teachers with an opportunity to become mentors. Whenever possible, teachers mentor within their school to build technology integration capacity by applying the skills and knowledge gained in the TIES courses. They implement standardsbased technology learning opportunities based on current research and assist their 'mentees' with their technology needs. The 'mentees' are pre-service or in-service teachers who would like to implement standards-based technology learning experiences for their students. The mentoring practicum course can be repeated, so mentors can continue to positively impact upon those within their schools. This course does not take place until the teacher returns to the classroom, enabling the TIES training to be reinforced. The TIES Technology Mentoring Practicum course is intended to build standardsbased technology competence through developing a support structure for mentors to become change agents while continuing their own professional development. Once a mentor is established, schools will be viable environments of life-long learning creating a 'win-win' situation for the mentor, the 'mentee' and the school.

\subsection{Best practice models of technology use}

The provision of concrete examples of technology integration is an important element of the TIES curriculum. LEI Aloha's ETEC-Connections 
web-site (www.hawaii.edu/etec-connections) provides streamed videos with standards-based lesson plans to showcase exemplary technology-based projects from various grade levels, subject areas, and schools in Hawai'i. An 'Overview Video' previews a project in an engaging and informative manner, encouraging viewers to pursue more detailed information. The 'Feature Video' provides the details through a teacher explanation of the project design, methodology and application, assessment strategies, community involvement, as well as the challenges and the various elements related to success in implementation. The resource kit includes assessment rubrics, teaching techniques, equipment and software tips, tutorials, samples of student work, and advice on grants or other funding approaches. 'Bookends of War,' for example, records the work of a fifth grade class at a local elementary school as the children explore the Arizona and Battleship Missouri memorials as place-markers for the beginning and ending of World War II. The project includes a curriculum mix that meets standards in a variety of subjects including technology, while it blends classroom work with lab development, guest speakers, and a field trip. The videos provide complete examples for on-line group or class discussion and evaluation. The resulting discussions create valuable opportunities for brainstorming, problem-solving, and stimulation to inspire further exploration.

It is also critical for students to gain experience in solving problems in dealing with situations of a more open-ended nature. 'Trigger Videos' included in the TIES courses provide teachers with the challenge of finding viable solutions to unanswered or incomplete scenarios. The open-ended approach demonstrated by these productions provides student teachers with a pattern to apply to problem-solving. It stimulates creativity and vision for resolving potentially real dilemmas that ultimately arise in a complex mix of curriculum objectives, technology, and the individual and team dynamics of the classroom.

\section{CONSIDERATION OF STAKEHOLDERS}

Careful thought was put into the value for stakeholders with interests in the TIES program. The creation of TIES followed a 'win-win' System of Reciprocity (Fulford and Eichelberger, 2001), where all stakeholders feel they gain something worthwhile. TIES addresses specific goals of a number of stakeholders including individual teachers, individual kindergarten-12 $2^{\text {th }}$ grade (K-12) schools, the Hawai'i DOE, the UH COE, and community colleges throughout the state.

$\mathrm{K}-12$ teachers are the principal consumers of TIES. These teachers are interested in intense application of technology according to the standards 
they are evaluated by as teachers. They also want a flexible programme to accommodate their teaching loads. Courses need to be accessible geographically as well. Finally, teachers who are investing their own money are interested in professional development credits granted by the Hawai' $i$ DOE which lead to salary increases. TIES was created to be a flexible programme capable of being tailored to either a year long course, a semester plan of study, completed during a sabbatical leave, or completed in addition to teaching loads. Further participation in the optional practicum course provides the necessary credits for advancement to the next salary level. TIES provides a profitable arrangement for $\mathrm{K}-12$ schools as the programme trains teachers to mentor other teachers in their school and provides a means for rewarding such mentoring. This makes the programme well worth the loss of a valuable teacher for the relatively short period of time. Thus, a particular school can invest in one teacher and reap professional development benefits for the entire school.

The Hawai'i DOE has as its focus the improvement of classroom environments, an increase in the number of valuable sabbaticals, and the alignment of university courses to standards-based teaching. The information given to teachers regarding TIES is presented in a format consistent with the state sabbatical leave applications. This makes the sabbatical application process easier for both the applicant and the reviewers. Participation of interested teachers in a cohesive, standards-based programme such as TIES improves the quality of sabbaticals for the State.

The COE at $\mathrm{UH}$ needs a pool of technology mentor teachers to better facilitate their placement of students in field experiences that provide quality mentoring in technology integration. The purpose of TIES is to create technology mentor teachers and reward those teachers for participating as mentors. The practicum course provides a reward system for teachers needing additional credits to move up the pay scale. A partnership with all UH community colleges on other islands was developed to help address the potential inequality among students by providing a way to make technology resources accessible to students in TIES and other COE outreach courses. The project-based component of TIES, offered through the community colleges, provides an accessible mentor to facilitate the on-line courses. In return, such courses generate revenue for the community colleges and can be offered to other students. Providing TIES as a sabbatical and encouraging students'participation through community colleges increases their enrolment. Producing change in educational settings is not the work of one institution alone, but is rather the co-operation of all stakeholders. TIES is a venture designed to address the needs of many partners interested in improving teachers' abilities to infuse technology into the learning environment responsibly, expertly, and creatively. 


\section{REFERENCES}

Carlson, R.D. and Gooden, J.S. (1999) Mentoring Pre-Service Teachers For Technology Skills Acquisition. Eric Document Reproduction Service No. ED 432280

Fulford, C. and Eichelberger, A. (2001) A System of Reciprocity: Empowering Stakeholders To Do More with Less in Educational Technology. Proceedings of the $7^{\text {th }}$ World Conference on Computers in Education, Copenhagen, Denmark.

Hinnant, E. (1997) Strategies for the integration of technology into teacher education programs. Technology Tools for Today's Campuses. Available at: http://horizon.unc.edu/projects/monograph/CD/

International Society for Technology in Education (1998) National Educational Technology Standards: Standards for Students. ISTE NETS Project. Eugene, OR: ISTE

International Society for Technology in Education (ISTE) (2000) National Educational Technology Standards (NETS) for Teachers. ISTE NETS Project. Eugene, OR: ISTE

National Council for Accreditation of Teacher Education (1996) National Standards for Technology in Teacher Preparation: ISTE accreditation and standards committee. Available at: http://www.iste.org/Standards/NCATE/index.html (Accessed August, 1999)

US Department of Education (1998) Teacher survey on professional development and training. National Center for Education Statistics, FRSS 65

\section{BIOGRAPHIES}

Catherine Fulford, Ph.D. is professor and project director of the LEI Aloha Catalyst Grant. She has received significant grant funding on similar projects for five years. Rachel Rivers, M.A. is LEI Aloha's project manager, and has played a significant role in the development of TIES and the sabbatical opportunity. Gary Theal, M.Ed. is the digital media manager, who has developed the extensive website and video resources. Celia MainAnakalea is a district resource teacher serving as a graduate intern, who initiated the partnership with the Department of Education Sabbatical Office and developed the original programme outline. 